\title{
Costumbrismo y novela en la segunda mitad del siglo XIX
}

ENRIQUE RUBIO CREMADES

Universidad de Alicante

El contexto literario de mediados del siglo XIX ofrece sutiles y peculiares matizaciones que configuran un especial comportamiento en el escritor de la época, actuando éste como receptor y continuador, en ocasiones, de ciertos géneros literarios que pasan inadvertidos en las amplias disecciones realizadas por los historiadores de la literatura. El estudio monográfico sobre autores y prensa en la década de los años cincuenta nos permite observar la transmutación paulatina - no rotunda - del cambio operado en la novela correspondiente a esta década, consciente el escritor de que un nuevo rumbo iba a transformar a la sociedad española. Temas como el de las crisis religiosas, adulterio, sociedad del «quiero y no puedo»..., ocuparán un lugar privilegiado en la narrativa de esta época. La sociedad circundante es objeto de minucioso estudio por parte de los novelistas de la segunda mitad del XIX, descrita y analizada con peculiar óptica y embadurnada con una cierta tendenciosidad que actuará como filtro en el complejo mundo novelesco. 
Novela y costumbrismo se dan en estos años desde una doble perspectiva; por un lado, el costumbrismo aislado que hace su aparición en periódicos como El Album Pintoresco, La Iberia, El Museo Universal, La América, El Imparcial, La Ilustración Universal, El Globo, etc., o en colecciones costumbristas pertenecientes a la segunda mitad del XIX. Las publicaciones pertenecientes a este segundo apartado intentan emular y continuar las ediciones existentes en la etapa romántica, superando con creces el éxito editorial de las colecciones anteriores.

Las palabras pronunciadas por Margarita Ucelay Da Cal al final de su excelente libro Los españoles pintados por sí mismos ${ }^{1}$ al afirmar que «los ecos de Los españoles pintados por sí mismos tuvieron larga resonancia en el mundo hispánico, y un estudio más demorado que éste de las colecciones derivadas de nuestro prototipo sería, sin duda, deseable y de interés ${ }^{2}$ motivan nuestro propósito y nos inclinan a sumergirnos en el estudio del costumbrismo de la segunda mitad del XIX, no enfocándolo desde una sola y única perspectiva, como sería la de su posible conexión con lo novelesco, como diría Montesinos en la Nota preliminar de su obra Costumbrismo y novela ${ }^{3}$, ni tampoco relegar las publicaciones costumbristas de la segunda mitad del XIX por creer que la historia del costumbrismo no ofrece grandes novedades a los investigadores del género una vez publicado el citado estudio - como afirmara Montesinos-; sin embargo, el mismo crítico afirmaría que «hay mucho que exhumar aún, y esas exhumaciones serán para el que las emprenda tarea más placentera que las que aquí nos impusimos» ${ }^{4}$. Según el criterio de Correa Calderón ${ }^{5}$ en su prólogo preliminar a la selección de textos que arranca con el entremés cervantino Rinconete y Cortadillo, su estudio no lo considera finiquitado, sino abierto a sutiles sugerencias de la crítica y lectores. Actitud que demuestra la vigencia de este género literario.

En este mosaico de críticas literarias en torno al costumbrismo -C. M. Montgomery, Lomba y Pedraja, Hendrix, Baquero Goyanes, José Luis Varela, J. Escobar, J. I. Ferreras, Lee Fontanella, etc.- des-

1 Margarita Ucelay Da Cal, Los españoles pintados por sí mismos (1834-1844). Estudio de un género costumbrista, Colegio de México, Fondo de Cultura Económica, 1951 .

2 Ibíd., p. 210.

3 José F. Montesinos, Costumbrismo y novela. Ensayo sobre el redescubrimiento de la realidad española, Madrid, 1960.

4 Ibíd., p. 138.

5 Correa Calderón, Costumbristas españoles. Estudio preliminar y selección de textos por ... , Madrid, 1964, p. CXXX. 
taca la importancia del género costumbrista dentro de ese conglomerado de corrientes literarias e ideológicas de la España del siglo XIX. Sin embargo, con la desaparición de los grandes maestros del costumbrismo romántico -Mesonero, Larra y Estébanez-, parece establecerse un rotundo corte entre el citado cost umbrismo romántico y el posterior desarrollo costumbrista, mereciendo especial atención los citados autores y las obras de los costumbristas anteriores - Liñán y Verdugo, Zabaleta, Santos, Clavijo y Fajardo, Miñano, etc.-. El corte vertical anteriormente aludido se establece con la aparición del realismo, siendo aquí precisamente donde la manifestación costumbrista es la gran desconocida por la crítica literaria. Esto tendría, creemos, su lógica explicación, pues el atractivo que ejercen los maestros del género -Mesonero, Larra y Estébanez, en especial-, tanto por su calidad como por su incidencia en la historia de la literatura, hace que el aluvión de costumbristas de segunda fila queden arrinconados. Otro tanto sucede con la publicación de colecciones costumbristas, pues el protagonismo lo ocupa Los españoles pintados por sí mismos, quedando en segundo término Los valencianos pintados por sí mismos, Las españolas pintadas por los españoles, Los españoles de ogaño, Madrid por dentro y por fuera...

Es interesante destacar a este respecto la clasificación dada por José Luis Varela para centrar el propósito de nuestro trabajo, aludiendo, por ello, al último apartado de la cronología costumbrista que define como «Costumbrismo coincidente con el realismo literario (Antonio Flores, colecciones de tipos observados por varios autores)» ${ }^{6}$. Nuestro interés se centra en esta parcela, estudiando el costumbrismo de la segunda mitad del XIX sin desdeñar, como es lógico, la influencia de las colecciones costumbristas anteriores a 1850 y la presencia de autores tildados de maestros por la crítica y por los propios continuadores del género. De ahí que la huella de Larra, Mesonero o Estébanez esté latente en estas colecciones.

La primera publicación de importancia que trata de emular o seguir los pasos de Los españoles pintados por sí mismos ${ }^{7}$ es la titulada Los valencianos pintados por sí mismos ${ }^{8}$, siguiendo el camino trazado

6 José Luis Varela, «Prólogo al costumbrismo romántico», en La palabra y la llama, Madrid, 1967, p. 89.

7 Los españoles pintados por sí mismos, Madrid, 1843. Las citas de nuestro trabajo corresponden a la segunda edición, año 1852, llevada a cabo por el editor Gaspar y Roig.

8 Los valencianos pintados por sí mismos, Valencia, Imprenta de la Regenẹración, de don Ignacio Boix, 1859. 
por la anterior colección. Si en la edición de Boix (1843) inciden de forma directa las obras Heads of the People ${ }^{9}$ y Les Français peints par eux-mêmes ${ }^{10}$, podemos decir que la de Boix influye de manera decisiva en las posteriores colecciones aparecidas tanto en España como en el mundo hispanoamericano ${ }^{\text {". }}$ El extenso capítulo que abarca desde la publicación de la primera obra costumbrista española hasta la aparición de otra colección homónima en su título en $1915^{12}$, existe un largo proceso y preocupación por el reflejo y estudio de la sociedad circundante, predominando en todas ellas la preferencia por el tipo y olvidándose casi por entero de la escena. Sin embargo, tanto el subgénero tipo como el de la escena aparecen indistintamente en aquellos escritores que aun dentro de estar etiquetados como consumados novelistas dedican parte de su tiempo al género costumbrista. De los escritores pertenecientes al último tercio del XIX estaría José María Pereda con sus cuadros pertenecientes a las Escenas montañesas. Tipos y Paisajes y Tipos trashumantes. El mismo Carlos Frontaura en Las tiendas, Ramón de Navarrete, Galdós con sus Fisonomías sociales, Palacio Valdés con sus Aguafuertes, Salvador Rueda con sus escenas $E l$ patio andaluz y Granada y Sevilla. La nómina del 98 ofrece también un muestrario idéntico a la relación anteriormente citada; obsérvense, por ejemplo, los artículos de Unamuno incluidos en De mi país, o los que forman parte del corpus general de Azorín titulados Los pueblos, Alma española, España y Madrid. Guía sentimental. Casos parejos serían los de Salaverría, Luis Bello, Gutiérrez Solana, R. Gómez de la Serna, Federico Carlos Sáinz de Robles y otros tantos escritores que tal vez con cierta preferencia por la escena desdeñan al subgénero tipo, quedando este úl-

9 Heads ot the People: or Portraits of the English drawn by Kenny Meadows. With original essays by distinguished writers, London, Robert Tyas, 1840.

10 Les Français peints par eux-mêmes. Encyclopédie Morale du dix-neuvième siècle. París, L. Curmer, 1840-1842. Sin embargo, el primer intento de obra colectiva correspondería a la publicación Paris, ou Le livre des cent-et-un, París, Ladvocat, 1831-34. Las concomitancias entre ambas publicaciones y la influencia de esta última sobre Les Français... fueron estudiadas por Le Gentil en su obra Le poète Manuel Bretón de los Herreros et la Société Espagnole de 1830 a 1860, París, Hachette, 1909, pp. 244-245. Hendrix no ignora como Le Gentil que la idea de Heads of the People proceda de Le Libre des cent-et-un, tal se desprende de su trabajo «Notes on Collections of Types, a Form of Costumbrismo", Hispanic Review, vol. I, julio, 1933, núm. 3. pp. 215-216.

11 Vid., por ejemplo, Las habaneras pintadas por si mismas en miniatura, La Habana, Imprenta Oliva, 1847. Los cubanos pintados por sí mismos. Edición de lujo ilustrada por Landaluze, con grabados de D. José Robles, La Habana, Imprenta y Papelería de Barcina, 1852. Los mexicanos pintados por sí mismos. Tipos y costumbres nacionales por varios autores, México, Imprenta de M. Murguía, 1854.

Los españoles pintados por sí mismos. Revista España, Madrid, 1915. 
timo como protagonista único y exclusivo de las colecciones costumbristas.

El paréntesis establecido entre la edición de Boix y la de su homónima publicada en 1915 puede dar una idea al lector de los posibles vaivenes e incidencias de dichas colecciones en el público decimonónico. Se podría afirmar que las colecciones costumbristas conocen en la década de los años setenta una nueva etapa áurea, pues son muy tímidos los intentos continuadores de Los españoles pintados por sí mismos. Aunque dicha colección se publica en 1843, es necesario esperar hasta el año 1872 para ver una colección costumbrista - Los españoles de ogañoque intenta seguir los pasos de la primera. Como indica V. Suárez en la introducción de la misma, «Los españoles de ogaño, colección de tipos de costumbres, no es una obra hija del estudio y la meditación; escrita entre el bullicio y la agitación de la vida política, (casi todos sus jóvenes autores son periodistas en activo servicio,) quizás no hallarán Vds. en la mayoría de sus páginas galana forma ni corrección de estilo, pero en cambio encontrarán dibujados con un esprit y una exactitud admirables, los infinitos tipos que en este último tercio del siglo XIX pululan por España y que estaban deseando verse reunidos en un par de tomos, como hace algunos años se vieron Los españoles pintados por sí mismos, obra que con más propiedad debe llamarse hoy Los españoles de antaño» ${ }^{13}$.

La incidencia editorial por las ediciones costumbristas en la década de los setenta es significativa con sólo fijarse en la cadencia de las publicaciones. Por ejemplo, Las españolas pintadas por los españoles ${ }^{14}$ aparece en los años 1871-72; Las mujeres españolas, portuguesas y americanas $^{15}$, en los años 1872, 1873 y 1876; Madrid por dentro y por

13 Los españoles de ogaño. Colección de tipos de costumbres dibujados a pluma, Madrid, Librería de Victoriano Suárez, 1872, vol. I, p. 5.

14 Las españolas pintadas por los españoles. Colección de estudios acerca de los aspectos, estados, costumbres y cualidades generales de nuestras contemporáneas. Ideada y dirigida por Roberto Robert, con la colaboración de ..., Madrid, Imprenta de J. M. Morete, 2 vols. 1871-72.

15 Las mujeres españolas, portuguesas y americanas. Tales como son en el hogar doméstico, en los campos, en las ciudades, en el templo, en los espectáculos, en el taller y en los salones. Descripción y pintura del carácter, costumbres, trajes, usos, religiosidad, belleza, defectos, preocupaciones y excelencias de la mujer de cada una de las provincias de España, Portugal y Américas Españolas. Obra escrita por los primeros literatos de España, Portugal y América, e ilustrada por los más notables artistas españoles y portugueses, Madrid-La Habana-Buenos Aires, Imprenta y Librería de D. Miguel Guijarro, 3 vols., 1872, 1873 y 1876. 
fuera ${ }^{16}$, en 1873, y Los hombres españoles, americanos y lusitanos pintados por sí mismos ${ }^{17}$, entre 1880 y 1882 . En contrapartida, la edición de 1843 provoca en los años cuarenta tímidas imitaciones. Sería el caso de El Album del bello sexo ${ }^{18}$, que por la fecha de publicación - 1843sería, más que imitación, intento competitivo con la edición de Boix, intento porque tan sólo salieron dos entregas, una firmada por Gertrudis Gómez de Avellaneda titulada «La dama de gran tono» y la segunda por Antonio Flores, «La colegiala». La colaboración de este último está en total contradicción con el propósito inicial de la obra -mujeres pintadas por sí mismas-; lo cierto es que tras la publicación de esta segunda entrega no existen visos de continuación, aunque en un principio la colección debía de constar de dos volúmenes con cuarenta tipos cada uno, publicándose al igual que Los españoles pintados por sí mismos por entregas. Ocho años más tarde aparece la edición de Los españoles..., año 1851 y no como indicara José F. Montesinos en $1871^{19}$, edición que lejos de superar a la editio princeps ofrece peor calidad en los grabados, papel y disposición del texto, pues el paginado aparece a dos columnas y la letra considerablemente reducida, con lo que se produce una cierta fatiga en el lector ${ }^{20}$. Las resultas son de fácil explicación: abaratar el coste de la edición en perjuicio y merma del lector.

16 Madrid por dentro y por fuera. Guía de forasteros incautos. Misterios de la Corte, enredos y mentiras, verdades amargas. Fotografías sociales. Tipos de Madrid, señoras y caballeros, políticos y embusteros. Lo de arriba, lo de abajo y lo de dentro. Madrid tal cual es. Madrid al pelo, etcétera. Dirigido por Eusebio Blasco y escrito por varios autores, Madrid, 1873.

17 Los hombres españoles, americanos y lusitanos pintados por sí mismos. Colección de tipos y cuadros de costumbres peculiares de España, Portugal y América, escritos por los más reputados literatos de estos países, bajo la dirección de don Nicolás Díaz de Benjumea y don Luis Ricardo Fors, e ilustrada con multitud de magníficas láminas debidas al lápiz del reputado dibujante don Eusebio Planas, Barcelona, s. a. (¿1881?).

18 El Album del bello sexo o las mujeres pintadas por sí mismas, Madrid, Imprenta de El Panorama Español, 1843. Se trata de una curiosa rareza bibliográfica y tan sólo hemos visto un ejemplar de esta publicación, encontrándose en la Hemeroteca Municipal de Madrid, signatura AH/15/1.

19 José F. Montesinos, op. cit., p. 133. Palau y Dulcet y M. Ucelay Da Cal ofrecen la fecha de 1851. De igual forma en Los mexicanos pintados por si mismos se alude a la edición de Gaspar y Roig fechada en 1851. Otro tanto ocurre con los anuncios publicitarios de la prensa del momento.

20 El ejemplar utilizado es de nuestra propiedad. M. Ucelay Da Cal, op. cit., p. 108, al hablar de esta edición desconoce la encuadernación original, al afirmar que el único ejemplar existente en la Biblioteca de Nueva York, el de la Hispanic Society of America, no la conserva. La encuadernación es en rústica, sin ningún alarde editorial, contrastando enormemente con la edición de Boix y con posteriores ediciones costumbristas. Los artículos aparecen en un volumen en $4 .^{\circ}$ mayor, con 382 páginas más una al final, en la que aparece el Indice de las materias que contiene esta obra, una lámina y cien grabados. 
A finales de la década de los cincuenta - 1859- Boix emprende la tarea de coleccionar los tipos más representativos de la ciudad y huerta valenciana, publicando la obra Los valencianos pintados por sí mismos $^{21}$. En lo concerniente a la calidad literaria vemos grandes altibajos entre los colaboradores, algunos cuadros de gran belleza y otros en donde la premura periodística parece surtir efectos negativos. Así como en la edición de Los españoles... se aglutinan escritores de todas las provincias, colaborando tanto los maestros consagrados como los noveles y prometedores escritores —sería el caso, por ejemplo, del ilicitano Antonio Flores-, en la colección de Los valencianos... la casi totalidad de los colaboradores son oriundos de Valencia, de ahí que la magna empresa se resintiera en ocasiones al reservar ciertos cuadros a escritores o periodistas que el tiempo ha olvidado o arrinconado por su escaso valor literario.

En la presente colección predominan los tipos populares, enunciándose el tipo u oficio con un título suficientemente expresivo que sirve de antesala informativa al lector. El título aparece indistintamente escrito en castellano o en valenciano, aunque el corpus general de la obra aparezca en castellano. Artículos cuyos rótulos aparecen en valenciano serían La carabasera, El foguerer, El clavari de las festes de carrer, La peixcaora, El chiquet de San Visént, El granerer, El tramuser, El palleter, El torrentí, El portaviolons, El corredor de choyes, El formacher, El pillet de mercat... Otros aparecen rotulados en castellano, aunque, como es lógico su contenido sea típicamente valenciano: $E l$ síndico del Tribunal de las Aguas, El barquero de la Albufera, El cohetero, El aristócrata valenciano, etc. Incluso hay artículos en los que se repara en esta salvedad, afirmándose que más de uno «debiera escribirse en valenciano puro y con la pluma de Clérigues, de Angles, de Bonilla, de Baldoví o de Liern»" ${ }^{22}$.

En la mencionada colección no existe preocupación por los tipos políticos, rasgo muy parecido al de Los españoles pintados por sí mismos, predominando, por el contrario, los distintos oficios populares inherentes a la personalidad valenciana. Rasgo por otro lado peculiar en el género costumbrista, donde lo popular tiene siempre una mayor cabida. Como contrapartida, los tipos u oficios pertenecientes a la mesocracia o nobleza ocupan un lugar accesorio, pasando casi inadverti-

2 Los valencianos pintados por sí mismos. Obra de interés y lujo escrita por varios distinguidos escritores, Imprenta de la Regeneración Tipográfica, de don Ignacio Boix, Valencia, 1859. Existe una edición facsímil realizada en Valencia en 1978 por Artes Gráficas Soler.

22 Vid. el artículo de Vicente Boix titulado El dulzainero, p. 27. 
dos. Sería el caso de los artículos El hacendado valenciano y El aristócrata valenciano, de C. Calvo Rodríguez y N. del Villar, respectivamente.

El protagonismo lo ocupan, pues, los tipos populares y aunque existe una gran condescendencia en la forma de tratar su comportamiento y maneras hay, en raras ocasiones, una cierta prevención hacia el tipo descrito; un ejemplo sería el cuadro El barquero de la Albufera, que en cierto modo guardaría paralelismo con la intencionalidad que guió en su día a Liñán y Verdugo a la hora de escribir Guía de avisos de forasteros que vienen a la Corte:

Vosotros, los que leáis estos renglones, y no estéis iniciados en los secretos de
la Albufera; huid de los barqueros del Saler iporque ellos se burlarán de
vuestra lengua y vuestro traje, harán suyas vuestras municiones y comida, os
depositarán en el puesto que encuentren más próximo, aunque en él sea más
fácil cazar aves del paraíso que patos; os verán achicharrados por el sol mien-
tras ellos duermen a la sombra en el fondo de su barca, y por último, os deja-
rán en tierra tan llenos de cansancio como de fastidio, para ir a referir el lance
a sus compañeros y reírse juntos de los que llevan a los cazadores viejos, y
que cobran muchísimo menos trabajando en cambio mucho más ${ }^{23}$.

Los tipos descritos en Los valencianos... hacen gala, por lo general, de probada astucia e inteligencia, aunque tal vez sea el primer rasgo el que predomine sobre el segundo, siendo el padre o tutor el encargado de transmitir a su heredero los complicados entresijos y astucias aprendidos en la práctica del oficio, como sucede, por ejemplo, en El dulzainero, El tamborilero, El arenero, El maderero, etc. Oficios por otro lado que están en trance de desaparecer, como indica el anónimo prologuista de Los valencianos.... Intencionalidad, por otro lado, característica del autor costumbrista que observa con no poca añoranza la pérdida de ciertas costumbres de nuestros antepasados:

Escribimos para la posteridad, y también para nuestros contemporáneos. $\mathrm{Pa}$ gamos un tributo a las bellezas que nos legaron los árabes; fijamos una imagen fugitiva, antes que la borre la pesada mano del tiempo; y disecamos, por decirlo así, para conservarlas, varias plantas indígenas, que de otra suerte amenazan agostarse, y confundirse con el polvo que las produjo. Hasta qué punto el pintor y el disector hayan salido airosos en su propósito, no son ellos los llamados a fallar. Lo son los españoles que lean la obra, y con cuyas simpatías a favor de ella contamos anticipadamente, no menos que con una benevolencia, cuya justificación reside en la índole, tendencias, y fin del libro que se les somete. Por eso acometimos confiadamente la empresa, por eso le damos cima; y por eso los Valencianos comparecen como son, ante el gran jurado nacional, del que a su vez no tarden quizá en formar parte, para juz-

23 El barquero de la Albufera, p. 201. 
gar y aprender de los demás, así como los demás pueden ahora estudiarlos a ellos, y sacar del estudio enseñanza provechosa ${ }^{24}$.

Por regla general los tipos aquí descritos guardan estrecho parentesco con la colección Los españoles... como se indica en el prólogo. Si ya apuntábamos con anterioridad la fuerte presencia de los tipos populares en estas colecciones, creemos en este momento oportuno decir que la técnica utilizada a la hora de describir el tipo estudiado es prácticamente idéntica a la de Los españoles. De ahí que no falte la consabida digresión al comienzo del cuadro con toda suerte de datos históricos; sirva de ejemplo El síndico del Tribunal de las Aguas:

Sabéis que aquel grupo se llama el Tribunal de las Aguas. Esa institución, vestida hoy de chaqueta, pantalón estrecho y sombrero redondo, nació por los años 911 al 976, bajo el gobierno de Abderrhman-Anasir-Ledinala y de su hijo Alhaken Almostansir Bilah. Estos nombres os darán a entender que la institución que os llama la atención, nació con turbante y alquicel ${ }^{25}$.

A continuación el autor ofrecerá fielmente el retrato del personajeprotagonista. Primero, su porte físico y ademanes; más tarde, la vestimenta utilizada para el cumplimiento del trabajo $u$ oficio realizado. Con estas premisas se suele empezar el artículo para ofrecer con no poca rapidez la práctica de ese mismo oficio. Todo se nos muestra como un rico mosaico de las costumbres de nuestros antepasados, costumbres salpicadas con anécdotas y personajes que hicieron de tal o cual profesión motivo de orgullo, como si realmente se hablara de múltiples castas que configuran la idiosincrasia particular del valenciano.

La redacción de los mismos no siempre aparece en prosa, sino que algunos hay que están escritos en verso, dándose también el cuadro misceláneo y con versos tanto con distinto cómputo silábico como intercalando varios pasajes en prosa. Esto se ofrece con cierta frecuencia en las colecciones costumbristas decimonónicas, tomando como modelo la primera colección aparecida en España - Los españoles...-. Ya en esta edición tenemos cuadros escritos en verso - El calesero y $E l$ cartero- y cuadros que intercalan el verso y la prosa - El aprendiz de literato, La marisabidilla, El seise de la Catedral, La gitana, El ama de llaves y La nodriza-. En Los valencianos pintados por sí mismos se continúa esta tradición, apareciendo indistintamente las modalidades anteriormente reseñadas. Cuadros en verso serían los escritos por Cristóbal Pascual y Genís, Peregrín García Cadena y Rafael Blasco ${ }^{26}$ y los

24 Prólogo, pp. 5-6.

25

26

El síndico del Tribunal de las Aguas, p. 101.

Los valencianos, op. cit., artículos «El granerer», «El coloquiero» y «El cocotero», respectivamente. 
escritos en verso y en prosa serían los de Pedro Yago, José Bernat Baldoví, Rafael Blasco y Filiberto Abelardo Díaz ${ }^{27}$. La modalidad de presentar artículos o cuadros en verso no es en verdad nueva en el XIX, siendo frecuente observar en la prensa del momento esta modalidad. Interminable sería la lista de los cuadros aparecidos en El Semanario Pintoresco Español, El Laberinto o El Museo de las Familias, periódicos, entre otros muchos, que dieron vida a infinidad de artículos de costumbres. Lo mismo sucede con el cuento en el siglo XIX, donde no existía una modalidad única, eligiendo el autor el verso o la prosa para su elaboración. En la actualidad la prosa ha suplantado al verso en el cuento, acostumbrándose el lector actual a esta última modalidad ${ }^{28}$.

Otro rasgo peculiar en Los valencianos pintados por sí mismos sería el de utilizar con cierta frecuencia valencianismos. El corpus general de la obra está escrito en castellano; sin embargo, aparecen muchas voces valencianas como rasgo inherente a la peculiaridad del tipo descrito. Los distintos oficios aquí trazados tienen una singular forma de pregonar su mercancía, como si se tratara de un medio rústico de publici$\operatorname{dad}^{29}$. Este procedimiento de anunciar el producto aparece en valenciano, así como los refranes o patronímicos del titular del cuadro. El autor o bien traduce entre corchetes la voz valenciana al castellano o en nota a pie de página explica el oficio o costumbre. Por ejemplo, en el cuadro La valenciana se explican entre corchetes los objetos o prendas que el esposo o la esposa debe aportar en la boda. De igual forma en La valenciana el producto recogido de la huerta se ofrece a los viandantes y futuros compradores con singular gracejo y presteza ${ }^{30}$.

La utilización del valenciano en estos artículos es idéntica a la de otras colecciones costumbristas, incidiendo de forma directa la lengua o dialecto del entorno social en el que se çircunscribe la acción. De ahí, por ejemplo, los galleguismos de El Album de Galicia o los dialectalismos del leonés o aragonés cuando el tipo o la escena tienen sus raíces en uno de estos puntos geográficos. Otro tanto sucede con la utilización del vulgarismo, gitanismo y el lenguaje de germanía en los cuadros si con ello se da un mayor realismo al tipo descrito. Modalidad utilizada en Los españoles pintados por sí mismos y que según la procedencia del personaje estudiado su lenguaje estará en perfecta consonancia con el

27 Ibid., artículos «El cafetero», «El turroner», «El coquiller» y «La panollera».

28 Vid. M. Baquero Goyanes, El cuento español en el siglo XIX, C. S. I. C., Madrid, 1949.

29 Vid. Antonio Flores, «Los gritos de Madrid», en Ayer, Hoy y Mañana, Barcelona, Montaner y Simón, 1892, pp. 419-428.

30 Vid., por ejemplo, el artículo «La valenciana», p. 395. 
tipo de sociedad en el que ha convivido. No extraña, pues, como sucede en Los españoles..., que los habitantes de los barrios del Barquillo o del Avapiés hagan gala de un lenguaje achulapado y castizo. Rasgo por otro lado que se proyecta en la novela de la segunda mitad del XIX cón gran insistencia, de ahí que el casticismo madrileño, plagado de distorsiones sintácticas y vulgarismos, se utilice en el mundo novelesco galdosiano, al igual que las novelas de Pereda, Pardo Bazán o Blasco Ibáñez al recoger las formas peculiares, patronímicos, sentencias o refranes que guardan estrecha vinculación idiomática con el personaje descrito. $29 / 4$

Ciñéndonos a Los valencianos... podemos comprobar cómo el recurso utilizado por los colaboradores de esta colección se repite en el posterior novelar de Blasco Ibáñez. De ahí la inclusión esporádica y aislada de valencianismos en Arroz y tartana, Flor de Mayo, La barraca, Entre naranjos, Cañas y barro, o en Cuentos valencianos y en La condenada y otros cuentos. Peculiaridad que lejos de desaparecer se repite en escritores posteriores. Circunscribiéndonos a nuestro entorno geográfico podríamos señalar el caso de Miró que ya en sus primeros ensayos novelísticos - La mujer de Ojeda e Hilván de escenas- utiliza dicho recurso con no poca insistencia ${ }^{31}$. Pero tal vez sea el caso más conocido y repreșentativo el de Blasco Ibáñez que no sólo recoge esta modalidad, sino que da vida novelesca a estos tipos y los desarrolla magistralmente en los Cuentos valencianos. Las colecciones costumbristas ofrecen en su totalidad un amplio muestrario de costumbres y usos, peresentándolos de forma aislada y sin introducir una trama argumental que aproximaría el artículo o cuadro costumbrista al género cuento. Según la mayor o menor dosis argumental recogida en el artículo costumbrista, éste podría aproximarse al cuento, como sucede en El retrato, La capa vieja y el baile del candil, Los cómicos de Cuaresma, De tejas arriba, etc. de Mesonero Romanos o El castellano viejo y El casarse pronto y mal de Larra, El asombro de los andaluces o Manolito Gázquez el sevillano, de Estébanez Calderón, ejemplos representativos de los muchos que encontramos en el costumbrismo ${ }^{32}$.

Como hemos puesto de manifiesto, la perfecta ilación y continuación de los tipos estudiados en Los valencianos... tendrá su respuesta en los Cuentos valencianos de Blasco Ibáñez, dando vida a una serie de tipos y escenas que tendrán su propio marco argumental en esta colec-

31 Ejemplo parecido al del ilicitano Ramón Jaén en sus novelas La oración del huerto y L'Almanguená. Como ejemplo reciente de la incorporación de valencianismos en una colección costumbrista escrita en castellano sería la de Angel Miguel Alcaraz, Alicante, una ciudad en el recuerdo, Impresora Formal, México, 1974.

Vid. M. Baquero Goyanes, op. cit., pp. 95-102. 
ción de cuentos. Sirva de ejemplo el primero que inicia la serie, Dimo$n i$, trasunto fiel del cuadro de Los valencianos... titulado El dulzainero. El protagonista - Dimoni-, aquel tipo popular a quien la gente admiraba cuando tocaba su dulzaina vieja, se nos ofrece como un personaje lleno de vida que siente el desprecio y la admiración de la gente, que se amanceba con una mujer - la Borracha- y vive un idilio amoroso que raya en ocasiones en lo esperpéntico. La muerte de la Borracha hará que Dimoni toque sólo la dulzaina en el cementerio,testimoniando así su amor y provocando el estupor entre las gentes. Otro tanto sucede con Cosas de hombres, La cencerrada, La apuesta del esparrelló, Noche de bodas, Guapeza valenciana, El femater, En la puerta del cielo o en la colección La condenada y otros cuentos, como por ejemplo el titulado En el mar, narraciones que guardan estrecha vinculación y parentesco con Los valencianos... Si acaso una importante salvedad, mientras que en la colección no existen connotaciones de tipo político, en los cuentos de Blasco Ibáñez sí hay, por el contrario, implicaciones de tipo social. Sirva como muestra el cuento recientemente citado $-E n$ el mar- para comprobar que el oficio de pescador ya no aparece con tintes apacibles, sino todo lo contrario. El simbolismo de las luces del Casino a altas horas de la noche y el oficio del pescador que día tras día entabla su lucha con el mar, sirven de contrapunto y contraste para la denuncia y protesta social. La muerte del joven pescador -Antoñicoacentúa aún más lo que de trágico y patético hay en el ser humano. En lo concerniente a las novelas sucede otro tanto, emergiendo los problemas sociales, arrendatarios y laborales de las novelas que tienen como marco geográfico la huerta valenciana.

Lo mismo podríamos decir de los tipos femeninos aparecidos en la colección Las españolas pintadas por los españoles, produciéndose un trasvase entre los cuadros aquí descritos y las novelas publicadas en la segunda mitad del XIX. Comportamientos, usos y formas de vida se describen en esta colección que pretende ser el reflejo de la sociedad femenina observada desde la perspectiva del hombre. El fallido intento de El álbum del bello sexo o las mujeres pintadas por sí mismas debió de impulsar a Roberto Robert a encomendar la descripción de estos tipos a escritores y no a mujeres, consciente tal vez de que el número de escritoras no sería suficiente para la compilación total de los tipos estudiados. Sería necesario esperar a la colección dirigida por Faustina Sáez de Melgar, Las mujeres españolas, americanas y lusitanas pintadas por sí mismas, para que el protagonismo de los mismos lo ocuparan ellas en su doble plano: como autoras y como reflejo social. En Las españolas pintadas por los españoles aparecen firmas de muy distinto cuño, desde Galdós, máximo exponente de la novela de la segunda mitad del XIX, 
hasta Pérez Escrich, fiel representante de la novela de folletín que por aquel entonces cobraba un auge inusitado, reviviendo una segunda etapa áurea este subgénero literario. La incidencia de los maestros costumbristas románticos -en especial Mesonero Romanos y Larra- se observa en la citada colección. El artículo La viuda, de Antonio María de Segovia, nos recuerda por la forma de realizar la disección y clasificación del tipo al cuadro de Larra Los calaveras, publicado en la Revista Mensajero en junio de 1835. Segovia, al igual que Fígaro, clasificará a la viuda como si se tratara de una singular especie; los distintos apartados hablan por sí solos: viuda verde, viuda seca, viuda reincidente y viuda fantástica. Larra clasificará a su calavera en calavera silvestre y calavera doméstico, este último con sus «subespecies»: calavera lampiño, calavera-temerón, calavera-langosta, calavera-tramposo, calaveracura, viejo-calavera, mujer-calavera y calavera de buen tono. Casi de idéntico tono sería el cuadro de Carlos Frontaura, titulado La fea, también con su correspondiente clasificación. Existen otros tipos analizados desde una nueva perspectiva, estudiándose su comportamiento a través de la proyección del esposo, tal es el perspectivismo empleado por Galdós en los cuadros La mujer del filósofo y Cuatro mujeres ${ }^{33}$. En la presente colección se observa también una cierta actitud misógina en la casi totalidad de este mosaico social, atenuada en ocasiones por un tinte dulzón a la manera de El Curioso Parlante y en otras en mordaz sátira al estilo de Fígaro.

La colección Las mujeres españolas, portuguesas y americanas presenta tonalidades claramente folklóricas, desapareciendo por completo esta actitud misógina y ponderándose al máximo las cualidades aborígenes de la fémina correspondiente. La citada colección consta de tres volúmenes; los dos primeros dedicados a la mujer española y el último a las féminas representantes de América y Portugal. Observamos ya la desaparición de tipos que representan un oficio a la manera de Los españoles..., destacándose en gran manera el comportamiento y rasgos de la mujer descrita. Todos ellos llevan el signo laudatorio como si cada uno de ellos quisiera competir con los tipos descritos. La publicación, auténtico alarde editorial ${ }^{34}$, reúne escritores suficientemente conocidos, desde los más consagrados novelistas - Alarcón, Trueba,

33 Vid. mi artículo "Galdós y las colecciones costumbristas del siglo XIX», Actas del Segundo Congreso Internacional de Estudios Galdosianos, Ediciones del Excmo. Cabildo Insular de Gran Canaria, 1978, vol. I, pp. 230-257.

34 Ejemplar que, como casi la totalidad de las colecciones costumbristas, es de suma rareza bibliográfica. Tan sólo hemos llegado a conocer la existencia de un único ejemplar, el de la Biblioteca Nacional de Madrid. 
Valèra, etc. - hasta políticos - Cánovas, Castelar, Ríos Rosas-y articulistas, como V. Bécquer y Pellicer. Es significativo el tratamiento que de estos personajes femeninos hacen los novelistas, como si el tipo descrito en la colección tuviera más tarde feliz continuación en el posterior desarrollo del escritor. Sirva el ejemplo del cuadro titulado La mujer de Córdoba, en el que Valera realiza auténticos alardes gastronómicos que serán más tarde protagonizados por la heroína de Juanita la Larga ${ }^{35}$. O también cuadros que guardan estrecho parentesco en la descripción física con féminas que protagonizan más de una novela, como por ejemplo La mujer de Granada, de Alarcón, y Soledad, de El Niño de la Bola.

Con la publicación de $E l$ Album de Galicia $^{36}$ se cierra el paréntesis de las colecciones costumbristas de la segunda mitad del XIX, colección en cierto modo híbrida al ofrecer sus autores un tipo femenino similar al de Las mujeres españolas, portuguesas y americanas -sería el caso de E. Pardo Bazán con su artículo La gallega - o siguiendo las huellas de Los españoles pintados por sí mismos, como los cuadros de Rosalía de Castro, A. Neira de Mosquera o Lisardo Barreiro.

La conexión entre lo meramente novelesco y el estudio de los distintos tipos agrupados en estas colecciones costumbristas se produce con total perfección. Simbiosis que no sólo se da en la tipología del personaje descrito sino tabién en el peculiar lenguaje utilizado en ambos géneros. Si ya habíamos indicado con anterioridad el caso de Blasco Ibáñez, lo mismo sucede con Galdós. Sus novelas Misericordia o Nazarín - por citar sólo dos casos de los muchos existentes- están en estrecha conexión con el habla de los tipos populares del Madrid de la época descritos por Mesonero Romanos o Antonio Flores. Caso extensivo a Pereda entre su mundo novelesco y sus escenas costumbristas o el de E. Pardo Bazán en novelas como Los Pazos de Ulloa y La madre naturaleza. Lo mismo sucede con los tipos descritos en las citadas colecciones, como el cesante, la mojigata o los distintos oficios del Madrid de la época que aparecerán tanto en las presentes colecciones como en el mundo novelesco de la segunda mitad del XIX. El prototipo de cesante descrito por Gil de Zárate en Los españoles pintados por sí mismos sur-

35 El trasvase entre el tipo y escena del citado cuadro y la novela Juanita la Larga no sólo es apreciado por la crítica, sino también corroborado por el propio Valera en su rico y copioso epistolario.

36 El Album de Galicia, Ferrol, 1897. 
girá más tarde en las páginas galdosianas, personajes como Ramón de Villaamil o Ido del Sagrario - novelista por entregas, cesante y pálido como un cirio- surgirán en las novelas Fortunata y Jacinta, El doctor Centeno, Tormento y en Lo prohibido. Otro tanto ocurre con Aguado - La incógnita y Realidad-, con Simón Babel -Angel Guerra- y con don Basilio Andrés de la Caña, personaje que conoce sucesivas cesantías en su trasiego novelesco creado por Galdós en sus novelas $E l$ doctor Centeno, Fortunata y Jacinta, Miau y Angel Guerra. Nombres como Cornelio Malibrán y Orsini, Ramón del Pez, Gonzalo Torres, Juan Pablo Rubí, etc., servirán de ejemplo para la descripción del tipo que conoce el amargo pan de la cesantía. El cesante podría sustituirse por otros tipos como el de la mojigata, de tan ilustre tradición literaria. Recuérdense, por ejemplo, las féminas María de los Remedios Tinieblas -Doña Perfecta-, Felisita Casado - Angel Guerra-, Serafina Lantigua - Gloria y La de Bringas-, Eulalia Moncada - La loca de la casa-, Marcelina Polo - Doctor Centeno y Tormento-, etc. Tipos también populares que más tarde protagonizarán novelas de indudable calidad literaria, como la relación existente entre el cuadro La cigarre$r a$, publicado en Las mujeres españolas, americanas y lusitanas pintadas por sí mismas y la heroína de La tribuna, Amparo, narraciones de E. Pardo Bazán. Ejemplos que podrían ampliarse a otros escritores pertenecientes a la misma generación.

En lo que respecta al escenario, la relación entre cuadro costumbrista y novela es idéntica. La colección Los españoles de ogaño es un muestrario amplio de tipos con su correspondiente ambientación que tendrán su perfecto ajuste y desarrollo novelesco en Galdós;si el escenario costumbrista andaluz incide en Valera o en Alarcón, el entorno geográfico de Pereda o Blasco Ibáñez estará también presente en sus relatos, acoplándose la dosis descriptiva y costumbrista al desarrollo de la peripecia argumental.

Hay todavía mucho que exhumar, como diría Montesinos, en las colecciones costumbristas de esta época para el mejor conocimiento de la historia de la literatura; de ahí la necesidad de un análisis pormenorizado de las colecciones costumbristas - clasificación de tipos, procedimientos literarios, grabados, estratificación social, etc., etc.-, que debería realizarse de una manera monográfica y acompañada de los correspondientes repertorios alfabéticos de tipos, autores, dibujantes y grabadores. Circunstancia que permitiría rescatar del olvido a escritores hoy injustamente arrinconados en los estantes de las bibliotecas y hemerotecas en espera de mayor fortuna. Las incursiones costumbristas en la prensa de nuestro siglo son un fiel testimonio de la continuidad 
del género. Ramón Gómez de la Serna, con su Elucidario de Madrid y El rastro, o el recién y tristemente desaparecido Federico Carlos Sáinz de Robles, con su rico mosaico costumbrista madrileño, demuestran la permanencia y vigencia del género costumbrista. 